\title{
Alpha1-ACT Functions as a Tumour Suppressor in Hepatocellular Carcinoma by Inhibiting the PI3K/AKT/mTOR Signalling Pathway via Activation of PTEN
}

\author{
Hanzhang Zhu Qiaoyu Liu Junwei Tang Yu Xie Xiaoliang Xu Ruyi Huang \\ Yuanguangyan Zhang Kangpeng Jin Beicheng Sun
}

Liver Transplantation Centre of the First Affiliated Hospital and Collaborative Innovation Centre for Cancer Personalized Medicine, Nanjing Medical University, Nanjing, Jiangsu Province, P.R. China

\section{Key Words}

$\alpha 1-\mathrm{ACT} \cdot \mathrm{HCC} \cdot \mathrm{PTEN} \cdot \mathrm{PI} \mathrm{K} \cdot \mathrm{AKT} \cdot \mathrm{mTOR}$

\begin{abstract}
Background \& Aims: To investigate the expression and prognostic value of $\alpha 1-\mathrm{ACT}$ (Alpha1-antichymotrypsin) in patients with HCC (hepatocellular carcinoma) and identify the mechanism by which $\alpha 1-A C T$ inhibits proliferation and promotes apoptosis of HCC. Methods: We first measured $\alpha 1-A C T$ expression levels and determined their relationship with the clinicopathological characteristics and prognosis of patients with HCC.We then established stable HCC cell lines with both $\alpha 1-\mathrm{ACT}$ overexpression and knockdown and performed a functional analysis in vitro.We first examined the relationship between $\alpha 1-A C T$ and the PTEN/PI3K/AKT/mTOR pathway using Western blotting. Then, we determined whether $\alpha 1-$ ACT can directly bind to PTEN using co-immunoprecipitation. Finally, we measured $\alpha 1-A C T$ expression to evaluate its correlation with the PI3K/AKT/mTOR pathway-related apoptosis proteins in a xenograft tumour mouse model using immunohistochemistry. Results: The $\alpha 1-A C T$ expression level was significantly lower in the HCC tissues than in the paratumour tissues and was negatively positively correlated with the level of Ki67, AFP, the AJCC stage, tumour size and tumour invasion. The overexpression of $\alpha 1-A C T$ can inhibit cell proliferation and increase cell apoptosis by activating PI3K/AKT/mTOR-mediated apoptosis via binding to PTEN and activating it in vitro. Additionally, the overexpression of $\alpha 1-A C T$ can also increase the proportion of cells in the G0/G1 stage by increasing cyclin p21 expression and inhibiting the migration and invasion abilities of HCC cells by regulating MMP2 and MMP9. The xenotransplantation studies with nude mice also showed that overexpression of $\alpha 1-\mathrm{ACT}$ inhibited tumourigenesis and knockdown of $\alpha 1-A C T$ had the opposite effect. Conclusions: Our study demonstrates that $\alpha 1-A C T$ suppresses liver cancer development and metastasis via targeting the PTEN/PI3K/AKT/mTOR signalling pathway, which may be a potential target for therapeutic intervention in $\mathrm{HCC}$.

\section{H. Zhu, Q. Liu and J. Tang contributed equally to this work}

Beicheng Sun

Liver Transplantation Centre of the First Affiliated Hospital and Collaborative Innovation Centre for Cancer Personalized Medicine, Nanjing Medical University, Nanjing, Jiangsu Province (P.R. China), E-Mail sunbc@njmu.edu.cn
\end{abstract}

KARGER 


\section{Cellular Physiology Cell Physiol Biochem 2017;41:2289-2306 \\ \begin{tabular}{l|l} 
and Biochemistry Published online: April 26, 2017 & $\begin{array}{l}\text { C } 2017 \text { The Author(s). Published by S. Karger AG, Basel } \\
\text { www.karger.com/cpb }\end{array}$
\end{tabular} \\ Zhu et al.: $\alpha 1-$ ACT Inhibits Hepatocellular Carcinoma}

\section{Introduction}

Hepatocellular Carcinoma (HCC) is the third most common carcinoma worldwide, with an estimated incidence of approximately 288,000 new cases every year [1-3]. The pathogenesis of HCC is associated with chronic hepatitis $\mathrm{B}$, chronic hepatitis $\mathrm{C}$, excess alcohol, non-alcoholic steatohepatitis (NASH), and aflatoxin exposure [4]. Although both basic and clinical studies of liver cancer have made great progress, the regulating factors in the pathogenesis of hepatocellular carcinoma remain largely unexplored [5-7].

Alpha1-ACT, also known as Serpin peptidase inhibitor, clade A, member 3,is a plasma protease inhibitor and a member of the serine protease inhibitor class [8].Polymorphisms and mutations in this protein are associated with many diseases, such as alpha-antitrypsin deficiency, Parkinson's disease, multiple sclerosis, aneurysma, cerebral haemorrhage, heart failure and chronic obstructive pulmonary disease[8-10]. $\alpha 1$-ACT has been reported to localize to the nuclei of hepatic cells and control chromatin condensation and cell proliferation [11].Overexpression of $\alpha 1$-ACT inhibits the growth of HCC xenograft tumours in nude mice that are formed by Huh7 cells transfected with pLV- $\alpha 1-A C T-G F P$ [11]. However, the mechanism of the tumour growth inhibition and whether $\alpha 1$-ACT can regulate apoptosis of human hepatocellular carcinoma cell have not yet been explored.

Many signalling pathways, such as the mTOR signalling, ERK signalling, NF- $\kappa B$ signalling, and the p53 signalling pathways, have been shown to be involved in the occurrence of liver cancer $[12,13]$. Among these pathways,mTOR signalling is commonly over-activated and plays an important role in the stimulation of proliferation, survival, metastasis, and drugresistance in many cancer types [14-17].

Recent evidence indicates that inhibition of the PI3K/AKT/mTOR pathway by smallmolecule PI3K inhibitors primes the cancer cells to undergo mitochondrial apoptosis by tipping the balance towards the pro-apoptotic Bcl-2 protein, which results in increased mitochondrial outer membrane permeabilization. Thus, the mitochondrial apoptotic events play an important role in PI3K inhibitor-mediated sensitization for apoptosis [18-20].

PTEN (the phosphatase and tensin homologue), which acts as a phosphatase for PI3P and suppresses the PI3K/AKT pathway,and can directly inhibit tumour cell growth and invasion [21]. On the other hand, there isa negative feedback relationship between p-PI3K and PTEN, which indicates that a decrease in p-PI3K can also cause an increase in PTEN [22].

Therefore, it is important to investigate whether $\alpha 1$-ACT participates in the regulation of the development of HCC by suppressing some of the signalling pathways and acting on some proteins. In a preliminary study in large HCC tumour specimens, we found that overexpression of $\alpha 1$-ACT is associated with clinicopathological factors and correlated with better prognosis in Chinese HCC patients. Further studies demonstrated that overexpressed $\alpha 1$-ACT in HCC cells induces apoptosis and reduces proliferation by inhibiting the activation of PI3K/AKT/ mTOR signalling and the downstream apoptosis-related proteins, such as Bcl2,Bax,Bad and cleaved PARP. During our in vitro studies, we found that $\alpha 1$-ACT can decrease migration and invasion via suppression of the expression of matrix metalloproteinase2 (MMP2) and matrix metalloproteinase9 (MMP9). We also found that $\alpha 1$-ACT can directly bind to PTEN and activate it to inhibit the PI3K/AKT/mTOR pathway.Our results demonstrated that overexpressed $\alpha 1$-ACT can function as a tumour suppressor in HCC by targeting the PTEN/ $\mathrm{PI} 3 \mathrm{~K} / \mathrm{Akt} / \mathrm{mTOR}$ signalling pathway both in vitro and in vivo.

\section{Materials and Methods}

Experimental protocol approval

All experimental protocols were approved by the Research Bureau of Nanjing medical University. All the animal protocols were approved by the IACUC of Nanjing medical University.

Patients and tissue samples

A total of 96 pairs of HCC carcinoma and para-carcinoma tissues were obtained from HCC patients who received surgery in the First Affiliated Hospital of Nanjing medical University between January 2008 and 


\section{Cellular Physiology Cell Physiol Biochem 2017;41:2289-2306 \begin{tabular}{l|l} 
and Biochemistry Published 10.1159/000475648 & $\begin{array}{l}\text { (c) } 2017 \text { The Author(s). Published by S. Karger AG, Basel } \\
\text { www.karger.com/cpb }\end{array}$
\end{tabular} \\ Zhu et al.: $\alpha 1-$ ACT Inhibits Hepatocellular Carcinoma}

Table 1. Correlation of $\alpha 1-\mathrm{ACT}$ and Ki-67 expression with clinicopathological factors in HCC specimens. Statistical analyses were performed by the Pearson $\chi 2$ test, ${ }^{*} \mathrm{P}<0.05$ was considered significant

\begin{tabular}{|c|c|c|c|c|c|c|c|}
\hline \multirow{2}{*}{$\begin{array}{l}\text { Clinic pathological } \\
\text { factors }\end{array}$} & \multirow{2}{*}{$\begin{array}{l}\text { Number of } \\
\text { cases }\end{array}$} & \multicolumn{3}{|c|}{$\alpha 1-\mathrm{ACT}$} & \multicolumn{3}{|c|}{$\mathrm{Ki} 67$} \\
\hline & & Low & High & $\mathrm{P}$ & Low & High & $\mathrm{P}$ \\
\hline Gender & & 63 & 33 & & 46 & 50 & \\
\hline Female & 36 & 24 & 12 & 0.8678 & 20 & 16 & 0.2458 \\
\hline Male & 60 & 39 & 21 & & 26 & 34 & \\
\hline \multicolumn{8}{|l|}{ Age (years) } \\
\hline$<45$ & 39 & 24 & 15 & 0.1244 & 17 & 22 & 0.4794 \\
\hline$\geq 45$ & 57 & 39 & 18 & & 29 & 28 & \\
\hline \multicolumn{8}{|l|}{ HbsAg } \\
\hline Negative & 24 & 14 & 10 & 0.3851 & 10 & 14 & 0.7236 \\
\hline Positive & 72 & 49 & 23 & & 36 & 36 & \\
\hline \multicolumn{8}{|l|}{$\mathrm{AFP}, \mathrm{ng} / \mathrm{ml}$} \\
\hline$<400$ & 64 & 35 & 29 & 0.003047 & 35 & 22 & 0.001385 \\
\hline$\geq 400$ & 32 & 28 & 4 & $* *$ & 11 & 28 & $* *$ \\
\hline \multicolumn{8}{|l|}{ Cirrhosis } \\
\hline Negative & 26 & 14 & 12 & 0.138638 & 14 & 12 & 0.47842 \\
\hline Positive & 70 & 49 & 21 & & 32 & 38 & \\
\hline \multicolumn{8}{|l|}{ Tumor size, $\mathrm{cm}$} \\
\hline$<5$ & 55 & 30 & 25 & 0.0151 & 20 & 35 & 0.008714 \\
\hline$\geq 5$ & 41 & 33 & 8 & $*$ & 26 & 15 & $* *$ \\
\hline \multicolumn{8}{|l|}{ Tumor number } \\
\hline Singer & 57 & 35 & 22 & 0.2924 & 23 & 34 & 0.07283 \\
\hline Multiple & 39 & 28 & 11 & & 23 & 16 & \\
\hline \multicolumn{8}{|l|}{ AJCC stage } \\
\hline I-II & 59 & 32 & 27 & 0.0060 & 21 & 38 & 0.002272 \\
\hline III-IV & 37 & 31 & 6 & $*$ & 25 & 12 & $* * *$ \\
\hline \multicolumn{8}{|l|}{ Metastasis } \\
\hline Negative & 56 & 31 & 25 & $0.0221 *$ & 21 & 35 & 0.01564 \\
\hline Positive & 40 & 32 & 8 & & 25 & 15 & $*$ \\
\hline \multicolumn{8}{|l|}{ Invasion } \\
\hline Negative & 36 & 16 & 20 & 0.0007 & 23 & 13 & 0.01522 \\
\hline Positive & 60 & 47 & 13 & $* *$ & 23 & 37 & $* *$ \\
\hline \multicolumn{8}{|l|}{ Ki-67 } \\
\hline Low expression & 46 & 24 & 22 & & 0.007 & & \\
\hline High expression & 50 & 39 & 11 & & $* *$ & & \\
\hline
\end{tabular}

December 2015. All HCC specimens were collected in accordance with the protocols approved by the Ethics Committee of Affiliated Hospital of Nanjing Medical University. All the patients submitted written informed consent before participation. The clinical specimens were acquired in operating room immediately $(\leq 10$ $\mathrm{min}$ ) after resection of a tumour, flash frozen in liquid nitrogen, and stored at $-80^{\circ} \mathrm{C}$.No patient had a history of exposure to either radiotherapy or chemotherapy before the surgery, and no other co-occurring cancers were diagnosed. Histological grades were classified as well (grades I-II; $n=59$ ) and poorly (grades III-IV; $\mathrm{n}=37$ ), which were differentiated according to American Joint Committee on Cancer(AJCC) stage. The followup time for these patients ranged from 1 to 60 months from the date of surgery. The main clinicopathological characteristics of the patients are shown in Table 1.

\section{Antibodies}

The antibodies used for the Western blotting were as follows: mouse monoclonal anti- $\alpha 1$ ACT antibody (1:1000; Abcam, Cambridge, United Kingdom)mouse monoclonal anti-PTEN antibody (1:1000; Abcam, Cambridge, United Kingdom), rabbit monoclonal anti-MMP2 antibody (1:1000; Abcam, Cambridge, United Kingdom), rabbit monoclonal anti-MMP9 antibody(1:1000; Abcam, Cambridge, United Kingdom), rabbitpolyclonal anti-PI3Kantibody (1:1000; Abcam, Cambridge, United Kingdom), rabbit polyclonal anti-phospho-PI3K p85 antibody(1:1000; Abcam, Cambridge, United Kingdom), rabbit polyclonal anti-AKT antibody (1:1000; Abcam, Cambridge, United Kingdom), rabbit polyclonal antiphospho-AKT473 antibody(1:1000; Abcam, Cambridge, United Kingdom),rabbit polyclonal anti-mTOR antibody (1:1000; abcam, Cambridge, United Kingdom), rabbit polyclonal anti-phospho-mTOR antibody (1:1000; Abcam,Cambridge, United Kingdom),rabbit monoclonal anti-GAPDH antibody (1:1000;Cell SignallingTechnology, USA). The secondary antibody incubation was performed using horseradish peroxidase-conjugated IgG (Cell SignallingTechnology, USA) at a dilution of 1:2000. Rabbit polyclonal anti-P21(1:1000; Abcam, Cambridge, United Kingdom), rabbit polyclonal anti-PARP(1:1000; abcam, Cambridge, the), rabbit polyclonal anti-cleaved-PARP (1:1000; Abcam,Cam bridge, the United Kingdom), 


\section{Cellular Physiology Cell Physiol Biochem 2017;41:2289-2306 and Biochemistry Published online: April 26, $2017 \quad \begin{aligned} & \text { DOI: 10.1159/000475648 } 2017 \text { The Author(s). Published by S. Karger AG, Basel } \\ & \text { www.karger.com/cpb }\end{aligned}$ \\ Zhu et al.: $\alpha 1-$ ACT Inhibits Hepatocellular Carcinoma}

rabbit polyclonal anti-BAX(1:1000; Abcam, Cambridge, United Kingdom), rabbit polyclonal anti-BAD (1:1000; Abcam,Cambridge,United Kingdom), rabbit polyclonal anti-Bcl2(1:1000; Abcam,Cambridge, United Kingdom). The antibodies used for immunohistochemistry were as follows: mouse monoclonal anti- $\alpha 1$-ACT antibody (1:100; Abcam, Cambridge, United Kingdom), rabbit polyclonal anti-phosphoPI3K antibody(1:200;Abcam, Cambridge, United KingdoSm), rabbit polyclonal anti- BAX (1:100;Abcam, Cambridge, United Kingdom), rabbit polyclonal anti-BAD(1:100;Abcam, Cambridge, United Kingdom), rabbit polyclonal anti-cleaved-PARP (1:100;Abcam, Cambridge, United Kingdom), and rabbit polyclonal anti-Ki67(1:100; Abcam, Cambridge, United Kingdom).

\section{Immunohistochemistry}

The fresh tumour tissues were fixed in $4 \%$ paraformaldehyde and embedded in paraffin. The 5- $\mu \mathrm{m}-$ thick sections were dewaxed twice in xylene for $10 \mathrm{~min}$ and rehydrated in ethanol. The sections were washed with PBS (phosphate-buffered saline,pH 7.4) 3 times for $3 \mathrm{~min}$. Then, the slides were boiled in $10 \mathrm{mM} / \mathrm{L}$ citrate buffer ( $\mathrm{pH}$ 6.0) in an autoclave for $3 \mathrm{~min}$ for antigen retrieval. After slowly cooling, the sections were blocked by immersion in 3\% methanolic peroxide for $15 \mathrm{~min}$ and incubated with the following primary antibodies: antibodies against $\alpha 1$-ACT, p-PI3K, BAX,BAD,Ki67, cleaved PARP overnight at $4^{\circ} \mathrm{C}$, followed by horseradish peroxidase(HRP)-conjugated secondary antibodies. After washing with water, the slides were counterstained with haematoxylin, dehydrated, and mounted in resin mount.

All the slides were examined by 3 independent pathologists in a blinded manner without knowing any of the clinical and pathological information about the patients. For evaluating the expression levels of $\alpha 1$ ACT, p-PI3K, p-AKT, p-mTOR, Ki-67, p21, BAX, BAD and cleaved PARP, at least six high-power fields for each specimen were selected, and the cytoplasm or nuclear staining were examined under a high-power lens. In addition, more than 500 cells were inspected to determine the mean percentage of the signal-positive cells. To quantify the $\alpha 1$-ACTexpression, the H-score (histochemistry score) was calculated by the percentage of stained cells $\times$ staining intensity. The patients were divided into the two following groups: a high expression group (>medium value of all HCC H-score) and a lower expression group ( $\leq$ medium value of all HCC H-score) according to the $\alpha 1$-ACT expression.

\section{Cell culture}

Five hepatocellular carcinoma cell lines (Hep3B, HepG2, MHCC-97H, SMMC-7721 and Huh7) LO2 and 293T cells were purchased from the Shanghai Cell Bank of the Chinese Scientific Academy. These cells were cultured in DMEM high glucose culture medium(Gibco Company, USA) supplemented with 10\% foetal bovine serum (Gibco Company, USA) and 1\% penicillin/streptomycin (Gibco Company, USA). The cells were cultured in cell culture dishes (Thermo, USA) under a humidified atmosphere containing $5 \% \mathrm{CO} 2$ at $37^{\circ} \mathrm{C}$.

\section{Plasmid construction and transfection}

The pLV-GFP, 8.91 and VSVG plasmids that were used for the packaging of lentivirus are preserved in our laboratory. The G248-sh1- $\alpha 1$-ACT-GFPinterference plasmid and G248-sh2- $\alpha 1$-ACT-GFP plasmid were synthesized and provided by the JIKAI company(Shanghai, China). The pLV- $\alpha 1-A C T-G F P$ plasmid was synthesized and provided by GENEWIZ Company of gene technology (Shanghai, China).The lentiviral packaging systems for the three plasmids consisted of a mixed DNA solution (20 $\mu \mathrm{g}$ pLV-GFP,G248-GFP,

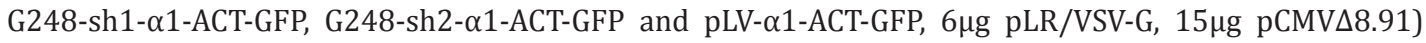
that was mixed well, and then sterile water was added to achieve the $500 \mu \mathrm{l}$ final volume. Then, $0.5 \mathrm{ml} 2 \times$ HBS phosphate buffered saline solution and $50 \mu \mathrm{CaCl}_{2}(2.5 \mathrm{mM} / \mathrm{L})$ were added to the DNA solution and gently mixed at room temperature for 20-25 min. The DNA mixture was then diluted with $5 \mathrm{ml}$ fresh DMEM containing 10\% FBS and 1\% penicillin/streptomycin and was used to transfer the 293T cells. After 6-8 h, the medium containing the DNA mixture was discarded and $10 \mathrm{ml}$ fresh DMEM was added to each culture dish. After $24 \mathrm{~h}$, the transfection efficiency was evaluated using fluorescence microscope. The supernatant of the $293 \mathrm{~T}$ cells was collected $48 \mathrm{~h}$ after the transfection. The cell supernatant was centrifuged at $1500 \mathrm{rpm}$ for 5 $\min$ at $4^{\circ} \mathrm{C}$ and then passed through a $0.45-\mu \mathrm{m}$ filter. At the time of the transfection, $5 \mathrm{ml}$ viral supernatant and $50 \mu \mathrm{L}(1 \mu \mathrm{g} / \mu \mathrm{L})$ polybrene were added to the $97 \mathrm{H}$ or Huh7 cells in $10-\mathrm{cm}$ cell culture plates. After 5 h, $5 \mathrm{ml}$ fresh DMEM containing 10\% FBS was added to every plate. After $24 \mathrm{~h}$, the medium was changed, and48 $\mathrm{h}$ later,the GFP expressed by cells was observed under a fluorescence microscope for evaluating the transfection efficiency. 


\section{Cellular Physiology Cell Physiol Biochem 2017;41:2289-2306 \\ \begin{tabular}{ll|l} 
and Biochemistry Published online: April 26, 2017 & $\begin{array}{l}\text { (c) } 2017 \text { The Author(s). Published by S. Karger AG, Basel } \\
\text { www.karger.com/cpb }\end{array}$
\end{tabular} \\ Zhu et al.: $\alpha 1-A C T$ Inhibits Hepatocellular Carcinoma}

\section{RNA extraction and Quantitative Real-time PCR}

Total RNA was extracted from the HCC tissues, paracancerous tissues and cell lines by using TRNzol-A ${ }^{+}$ Reagent according to the manufacturer's instructions (Tiangen Biotech Co., Beijing, China). The RNA from all the samples was reversed transcribed using a PrimeScript RT Master Mix kit (Takara, Tokyo, Japan). The mRNA levels of $\alpha 1$-ACT were determined by quantitative real-time PCR (qRT-PCR) and calculated using the $2^{-\triangle \Delta C T}$ method, with the CT values normalized using GAPDH as an internal control. The primers are as follows: $\alpha 1$-ACT, sense 5'-GCTCATCAACGACTACGTGAA-3' and anti-sense 5'-CACCATTACCCACTTTTTCTTGC3';GAPDH,sense 5'-GGAGCGAG ATCCCTCCAAAAT-3' and anti-sense 5'-GGCTGTTGTCATACTTCTCATGG-3'. Real-time RT-PCR was performed using a SYBR Green PCR Master Mix (Takara, Tokyo, Japan)in an ABI Prism $7900 \mathrm{HT}$ instrument(Applied Biosystems, CA, USA)according to the manufacturer's instructions.

\section{Cell proliferation analysis}

To study the role of $\alpha 1$-ACT in cell proliferation, we used G248-sh1- $\alpha 1-A C T-G F P$ and G248-sh2- $\alpha 1$ ACT-GFP to interfere with the expression of $\alpha 1$-ACT in the $97 \mathrm{H}$ cells, and we used the pLV- $\alpha 1$-ACT-GFP plasmid to overexpress $\alpha 1$-ACTin the Huh7 cells. Cell proliferation was analysed using a Cell Counting Kit-8 assay (CCK-8, Dojindo, Japan).

The Cell Counting Kit-8 assay was performed according to the manufacturer's instructions. Briefly, the cells were plated into 96 -well plates at a density of $2^{*} 10^{3}$ cells/well with $100 \mu \mathrm{L}$ culture medium. After adhesion, the cells were incubated for $0,24,48$ and $72 \mathrm{~h}$. At the end of each culture period, $10 \mu \mathrm{L}$ CCK- 8 reagent was added to each well and incubated for another $2 \mathrm{~h}$, and then the light absorbance was measured at a 450 -nm wavelength.

For the colony formation assay, the cells were plated into a 6 -well plate $\left(1 \times 10^{3} \mathrm{cells}\right.$ per well)and then cultured for 12 days. The colonies were stained with $0.1 \%$ crystal violet for 5 min after fixation with $4 \%$ paraformaldehyde for $10 \mathrm{~min}$. All the experiments were performed in triplicate.

\section{Analysis of apoptosis in cells}

The annexin V-PE/7-AAD apoptotic analysis of flow cytometry was used to analyse cell apoptosis. An Annexin V-FITC Apoptosis Detection Kit (BD Biopharmingen, NJ, USA) was used for flowcytometric analysis. The G248-GFP-, G248-sh1- $\alpha 1$-ACT-GFP-, G248-sh2- $\alpha 1$-ACT-GFP-transfected $97 \mathrm{H}$ cells and the pLV- $\alpha 1$-ACTGFP-, PLV-GFP- transfected Huh7 cells in the logarithmic phase were subjected to the annex in V-PE/7-AAD apoptotic analysis. For this analysis, approximately $3 \times 10^{4}$ cells in the logarithmic phase were digested by pancreatic enzymes containing no EDTA,washed in PBS and centrifuged at $1500 \mathrm{rpm}$ for $5 \mathrm{~min}$ at $4^{\circ} \mathrm{C}$ twice. The cells were then stained with annexin V-FITC for $15 \mathrm{~min}$ in the dark. All the experiments were analysed using a BD Biosciences FACSCalibur flow cytometer (BD Biosciences, NJ, USA). The tests were repeated three times, and triplicate wells were used for each condition.

\section{Cell cycle analysis}

The cell cycle analysis was performed using a Cell Cycle Staining Kit (Multisciences, China) following the manufacturer's instructions. Briefly, approximately $6 \times 10^{4} \mathrm{cells}$ in the logarithmic phase were digested with pancreatic enzymes, washed in PBS and centrifuged at $2000 \mathrm{rpm}$ for $5 \mathrm{~min}$ at $4^{\circ} \mathrm{C}$ twice. Then, the cells were fixed in $75 \%$ methanol for $4 \mathrm{~h}$ at $-20^{\circ} \mathrm{C}$, centrifuged at $1000 \mathrm{~g}$ for $5 \mathrm{~min}$ and then resuspended in 2 $\mathrm{ml}$ PBS for $15 \mathrm{~min}$.After that, the cells were centrifuged at $2000 \mathrm{rpm}$ for $5 \mathrm{~min}$ and washed with PBS three times. Subsequently, the cells were stained with $1 \mathrm{ml}$ DNA staining solution (Multisciences, China) for 30 min. Finally, a BD FACScan flow cytometer (Becton Dickinson, San Jose, CA, USA) coupled with the Cell Quest acquisition and analysis programs was used to analyse the cell cycle distribution.

\section{Cell migration and invasion assay}

We used a wound healing assay to evaluate the migration ability of the cells. For a wound healing assay, the HCC cells were seeded into six-well plates and allowed to grow to $80-90 \%$ confluence. A 200 $\mu \mathrm{L}$ sterile plastic tip was used to create a wound line across the surface of plates, and the cellular debris was removed by washing the plates with phosphate-buffered saline. The cells were cultured in DMEM in a humidified incubator under $5 \% \mathrm{CO} 2$ at $37^{\circ} \mathrm{C}$ for $72 \mathrm{~h}$, and then images were taken with a phase-contrast microscope at $0 \mathrm{~h}$ and $72 \mathrm{~h}$.

For the Transwell invasion assay, $2 \times 10^{4}$ cells suspended in DMEM without FBS were added to ECMatrixcoated inserts (Millipore,Billerica,MA)in 24-well companion plates with DMEM containing 20\% FBS and 


\section{Cellular Physiology Cell Physiol Biochem 2017;41:2289-2306 and Biochemistry Published \begin{tabular}{l|l} 
DOI: 10.1159/000475648 & $\begin{array}{l}\text { C } 2017 \text { The Author(s). Published by S. Karger AG, Basel } \\
\text { www.karger.com/cpb }\end{array}$
\end{tabular} \\ Zhu et al.: $\alpha 1-\mathrm{ACT}$ Inhibits Hepatocellular Carcinoma}

incubated for $48 \mathrm{~h}$. The cells and Matrigel in the upper chambers were removed with a cotton tip. The migrating and invading cells at the bottom of the filter were photographed under a light microscope after they were fixed with a $4 \%$ paraformaldehyde solution for $10 \mathrm{~min}$ and visualized after staining with a crystal violet solution for $30 \mathrm{~min}$. The number of invading cells in each chamber was quantified by counting five fields under $20 \times$ magnification.

Protein extraction and Western blotting

Whole cells were washed in PBS and lysed in RIPA lysis buffer(strong) supplemented with PMSF and a protease inhibitor cocktail (Nanjing KaijiBiology Development Co., Ltd., Nanjing, China). The total protein was quantified using a BCA Protein Assay Kit (Beyotime, Jiangsu, China).The total cell lysate was separated by SDS-PAGE and transferred to polyvinylidenedifluoride membranes (0.45 $\mu \mathrm{m}$, Millipore, Bedford, MA). The blotted membranes were blocked with Tris-bufferedsaline containing 0.05\% Tween 20 (TBST)and 5\% fat-free dry milk for $2 \mathrm{~h}$ at room temperature and incubated overnight with primary antibodies in TBST with $1 \%$ bovine serum albumin. After three 10-min washes with TBST, the membranes were further incubated for $2 \mathrm{~h}$ at room temperature with corresponding the horseradish peroxidase-conjugated secondary antibodies at the appropriate dilution. The immunoreactive protein bands were visualized by an ECL kit (Thermo, USA).

Co-immunoprecipitation(CoIP) assay

A RIPA lysis buffer(moderate) supplemented with PMSF and protease inhibitorcocktail (Nanjing Kaiji Biology Development Co., Ltd., Nanjing China) was used to lyse the cells after washing in PBS and to perform the immunoprecipitation. We used a Co-immunoprecipitation Kit(Thermo Fisher Scientific,Waltham,USA), rabbit monoclonal anti- $\alpha 1-A C T$ antibody (1:1000; Abcam, Cambridge, United Kingdom), mouse monoclonal anti-PTEN antibody (1:1000; Abcam, Cambridge, United Kingdom), mouse monoclonal anti-PI3K antibody (1:1000;Abcam, Cambridge, United Kingdom)for the Co-IP, and all the experimental steps were conducted according to the manufacturer's instructions.

\section{Xenograft tumourmouse model}

All mouse experiments were performed in accordance with the approved guidelines from the IACUC of Nanjing Medical University. The methods were carried out in accordance with the approved guidelines. Male BALB/c nude mice ( 6 weeks of age) were subcutaneously injected with the G248-sh1- 1 1-ACT-GFP- and G248-GFP-transfected 97H cells and the pLV- $\alpha 1$-ACT-GFP- and pLV-GFP-transfected Huh7 cells $\left(5 \times 10^{6} / 0.1 \mathrm{ml}\right.$ PBS) in separate groups ( $n=6$ per group). The tumour volumes were monitored every 2 days. The tumourbearing mice were sacrificed 40 days after inoculation, and the tumours were removed.

\section{Statistical analysis}

All results are presented as the mean \pm S.D. Student's t-tests were used to analyse significant differences between the samples. All the histograms were evaluated with GraphPad Prism software, version 4.0 (GraphPad, SanDiego California, USA). The statistical analyses were performed using Stata. 11.0. $\mathrm{P}<0.05$ indicated statistically significant differences.

\section{Results}

Reduced expression of 1 -ACT in the HCC tissue and HCC cells

The mRNA expression levels of $\alpha 1$-ACT in 96 paired HCC and adjacent non-tumour tissues were examined by qRT-PCR and normalized to GAPDH. The results showed that $\alpha 1$-ACT mRNA levels were significantly decreased in the HCC tissues compared with the adjacent non-tumour tissues ( $\mathrm{p}<0.001$, Fig. $1 \mathrm{a}$ ). In addition, the protein levels of $\alpha 1$-ACT were measured by Westernblotting, and we found notably lower levels in the tumour tissues(Fig. 1b).By immunohistochemistry, we found that the cancerous tissues had significantly lower expression levels of $\alpha 1$-ACT than the adjacent non-cancerous liver tissues(Fig.1c).Moreover, the $\alpha 1$-ACT expression levels were significantly downregulated in all the HCC cell lines compared with thosein the normal foetal hepatocyte LO2 cells ( $p<0.05$,Fig. 1d). These 


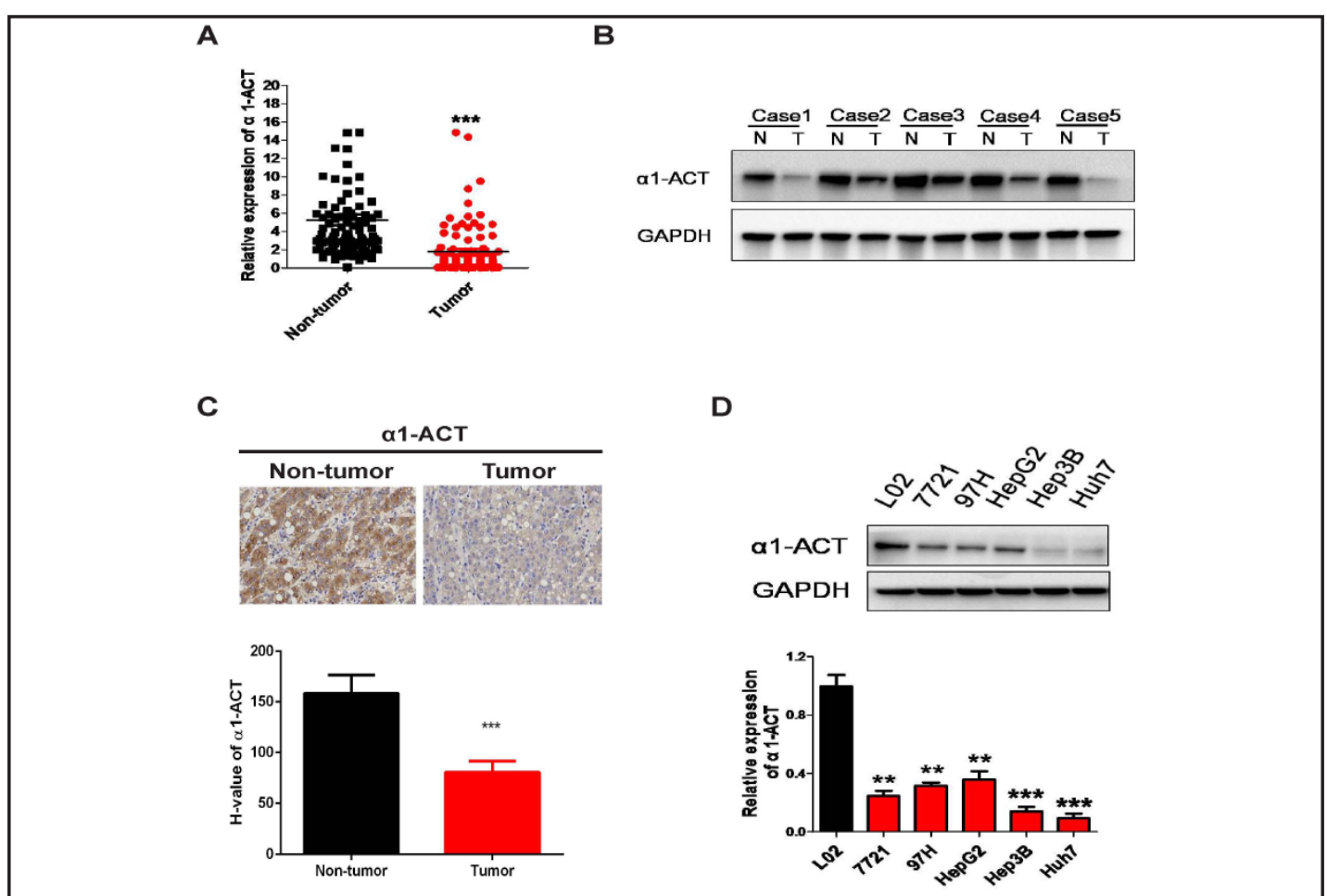

Fig. 1. The expression level of $\alpha 1$-ACT decreased in the HCC tumour cells. (A) qRT-PCR showed the downregulation of the mRNA levels of $\alpha 1$-ACT in 96 paired HCC tumours compared with the adjacent non-tumour tissues. ${ }^{* * *} \mathrm{p}<0.001$. (B) The protein level of $\alpha 1$-ACT decreased in 5 representative pairs of HCC tumours as determined by a Western blot assay. (C)The representative immunohistochemical staining of 1-ACT is significantly lighter in the HCC tumours than in the adjacent non-tumour tissues. The scale bar is $100 \mu \mathrm{m}$. (D) Both the protein (top) and mRNA (bottom) levels of $\alpha 1$-ACT were down-regulated in the HCC cell lines (7721, 97H, HepG2, Hep3B and Huh7)compared to the foetal hepatocyte cells (L02). ${ }^{* *} \mathrm{p}<0.01,{ }^{* * *} \mathrm{p}<0.001$.

findings indicated that the HCC tissues and liver cancer cell lines express low levels of $\alpha 1$ ACT.

Correlation between $\alpha 1-A C T$ expression and the clinicopathological variables in the patients with $\mathrm{HCC}$

To explore the pathophysiological relationship between $\alpha 1$-ACT expression and the tumour characteristics, the clinicopathological data are summarized in Table 1 . The results showed that the expression level of $\alpha 1$-ACT was significantly correlated with the level of AFP $(\mathrm{P}=0.019)$, the AJCC stage $(\mathrm{P}=0.02)$, tumour size $(\mathrm{P}=0.011)$ and tumour invasion $(\mathrm{P}=$ $0.016)$, while the expression level of $\boldsymbol{\alpha} 1$-ACT was not correlated with other factors, such as gender and age. Moreover, we also examined the correlation between the expression level of Ki-67 and the clinicopathological characteristics of the patients. We found that there was a significant correlation between the expression level of Ki-67 and the expression level of AFP $(\mathrm{P}=0.005)$ and the AJCC stage $(\mathrm{P}=0.009)$. However, the expression of Ki-67 was not correlated with other factors. Spearman's correlation coefficient was also used to analyse the relationship between the expression levels of $\alpha 1$-ACT and Ki-67 in the examined HCC tissues and indicated that there was a remarkable negative correlation between the expression levels of $\alpha 1$-ACT and Ki-67 (Fig. 2a). These results suggested that the down-regulated expression level of $\alpha 1$-ACT may contribute to the progression of HCC.

Prognostic significance of the $\alpha 1$-ACT expression levels

To explore the correlation between the expression level of $\alpha 1$-ACT and patient survival, Kaplan-Meier analysis was performed on the data from a total of 96 patients with follow-up 
Fig. 2. The expression level of $\alpha 1$-ACT was correlated with the outcome of HCC in patients. (A) Spearman's correlation coefficient analysis showed a negative correlation of the $\mathrm{H}$-score between the levels of $\alpha 1$-ACT and Ki67 in the HCC tissues $(\mathrm{R}=-0.565, \mathrm{P}<0.0001)$. The Kaplan-Meier analysis high $\mathrm{H}$-score of the levels of $\alpha 1$-ACT (B) and Ki-67 (C) were positively and negatively correlated with patient survival rates, respectively.

data. The survival curves revealed that the patients with HCC and low $\alpha 1$-ACT expression levels had poorer overall survival than those with higho1-ACT expression levels(Fig. 2b). However, elevated Ki-67 expression levels predicted significantly shorter overall patient survival (Fig. 2c). Moreover, we evaluated the association between the survival status of the patients and the clinicopathological parameters using univariate analysis and found

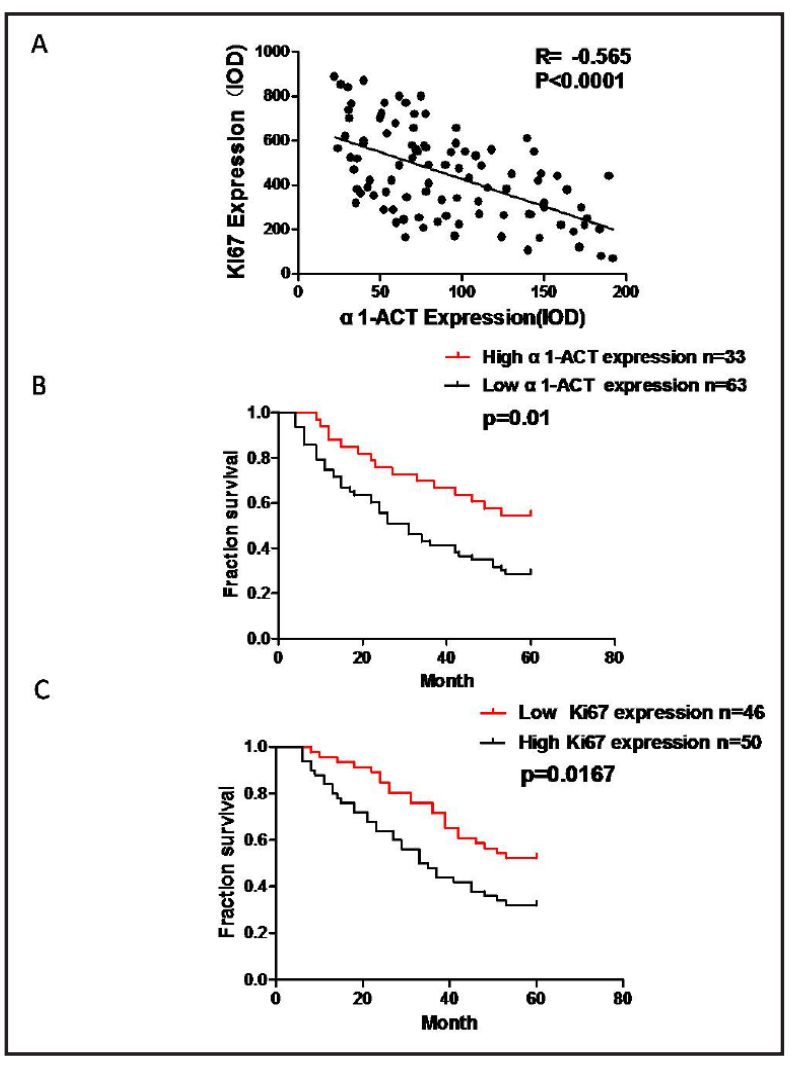
that there was a significant correlation between the survival status of the patients and the clinicopathological factors, such as the level of AFP $(\mathrm{P}<0.001)$, the AJCC stage $(\mathrm{P}<0.001)$, the expression level of Ki-67 ( $\mathrm{P}=0.002)$, and the expression level of $\alpha 1-\mathrm{ACT}(\mathrm{P}<0.001)$ (Table 2 ). Multivariate analysis showed that the tumour size $(\mathrm{P}=0.010)$, the AJCC stage $(\mathrm{P}<0.001)$, and the expression level of $\alpha 1$-ACT $(\mathrm{P}=0.020)$ were independent prognostic factors for the patients with HCC (Table 3). These data demonstrated that $\alpha 1$-ACT maybe a valuable prognostic indicator for the prediction of patient survival.

\section{$\alpha 1$-ACT regulated cell proliferation}

To understand the effect of $\alpha 1$-ACT on cell proliferation,the $\alpha 1$-ACT knockdown and overexpressed HCC cell lines were established as shown in Fig. 3 a and b. A Cell Counting Kit-8 (CCK-8) assay and a colony formation assay were performed. The CCK-8 assay showed that the proliferation of the HCC cells was significantly increased in the $\alpha 1$-ACT knockdown, stable $97 \mathrm{H}$ cells compared with the control cells (Fig. 3c), whereas the overexpression of $\alpha 1$ ACT reduced the proliferation of the Huh 7 cells (Fig. 3c).

The overexpression of $\alpha 1$-ACT in the pLV- $\alpha 1$-ACT-GFP-transfected Huh7 cells effectively decreased the colony number compared to the control G248-GFP-transfected group, and this effect was reversed in the G248-sh1- $\alpha 1$-ACT-GFP- and G248-sh2- $\alpha 1$-ACT-GFP-transfected 97H cells compared with the control G248-GFP- transfected cells.(Fig. 3d)

The above mentioned results indicated that $\alpha 1-\mathrm{ACT}$ can significantly regulate cell proliferation.

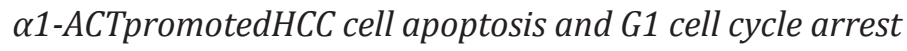

No previous studies have focusedon whethera1-ACT caninduce cell apoptosis. To answer this question, we used flow cytometry on theHCC cells toanalyze the role of $\alpha 1$-ACT inapoptosis.

The G248-sh1- $\alpha 1$-ACT-GFP-, G248-sh2- $\alpha 1$-ACT-GFP-, G248-GFP-transfectedgroups of the $97 \mathrm{H}$ cells and the pLV- $\alpha 1$-ACT-GFP-, pLV-GFP-transfected groups of the Huh7 cells in the logarithmic phase were subjected to annexin V-PE/7-AAD apoptotic analysis. The 


\begin{tabular}{|c|c|c|c|c|c|}
\hline \multirow{2}{*}{ Table 2. Correlation } & \multirow{2}{*}{$\begin{array}{l}\text { Clinic pathological } \\
\text { factors }\end{array}$} & \multirow[t]{2}{*}{ Total } & \multicolumn{2}{|c|}{ Survival status } & \multirow[t]{2}{*}{$\mathrm{P}$} \\
\hline & & & $\operatorname{Dead}(n=49)$ & Alive $(n=47)$ & \\
\hline thological factors & Gender & & & & \multirow{3}{*}{0.268278} \\
\hline thological factors & Female & 36 & 21 & 15 & \\
\hline and survival status & Male & 60 & 28 & 32 & \\
\hline inHCC specimens. & Age (years) & & & & \multirow{3}{*}{0.384086} \\
\hline & $<45$ & 39 & 22 & 17 & \\
\hline Statistical analyses & $\geq 45$ & 57 & 27 & 30 & \\
\hline were performed by & HbsAg & & & & \multirow{3}{*}{0.555604} \\
\hline the Pearson $\gamma^{2}$ test & Negative & 24 & 11 & 13 & \\
\hline & Positive & 72 & 38 & 34 & \\
\hline${ }^{*} \mathrm{P}<0.05$ was consi- & AFP, ng/ml & & & & \\
\hline \multirow{25}{*}{ dered significant } & $<400$ & 64 & 27 & 37 & 0.014117 \\
\hline & $\geq 400$ & 32 & 22 & 10 & * \\
\hline & Cirrhosis & & & & \\
\hline & Negative & 26 & 11 & 15 & \multirow{2}{*}{0.296809} \\
\hline & Positive & 70 & 38 & 32 & \\
\hline & Tumor size, $\mathrm{cm}$ & & & & \\
\hline & $<5$ & 55 & 21 & 34 & \multirow{3}{*}{$\begin{array}{l}0.003508 \\
* *\end{array}$} \\
\hline & $\geq 5$ & 41 & 28 & 13 & \\
\hline & Tumor number & & & & \\
\hline & Singer & 57 & 27 & 30 & \multirow{3}{*}{0.384086} \\
\hline & Multiple & 39 & 22 & 17 & \\
\hline & AJCC stage & & & & \\
\hline & I-II & 56 & 29 & 37 & \multirow{3}{*}{$\begin{array}{l}0.001807 \\
* *\end{array}$} \\
\hline & III-IV & 40 & 30 & 10 & \\
\hline & Metastasis & & & & \\
\hline & Negative & 77 & 34 & 43 & \multirow{3}{*}{$\begin{array}{l}0.013865 \\
*\end{array}$} \\
\hline & Positive & 19 & 15 & 4 & \\
\hline & Invasion & & & & \\
\hline & Negative & 36 & 12 & 24 & \multirow{3}{*}{$\begin{array}{l}0.007177 \\
* *\end{array}$} \\
\hline & Positive & 60 & 37 & 23 & \\
\hline & $\mathrm{Ki}-67$ & & & & \\
\hline & Low expression & 46 & 16 & 30 & \multirow{2}{*}{$\begin{array}{l}0.002238 \\
* *\end{array}$} \\
\hline & $\begin{array}{l}\text { High expression } \\
\alpha 1-\mathrm{ACT}\end{array}$ & 50 & 33 & 17 & \\
\hline & Low expression & 63 & 39 & 24 & \multirow{2}{*}{$\begin{array}{l}0.003262 \\
* * *\end{array}$} \\
\hline & High expression & 33 & 10 & 23 & \\
\hline
\end{tabular}

Table 3. Contribution of various prognostic factors to survival by Cox regression analysis on 96 HCC specimens. Statistical analyses were performed using log-rank test ${ }^{*} \mathrm{P}<0.05$ was considered statistically significant

\begin{tabular}{llll}
\hline Clinicopathological factors & Hazard ratio & $95.0 \%$ confidence interval & P value \\
\hline Gender & 0.76 & $0.47 \sim 1.05$ & 0.09 \\
Age (years) & 0.75 & $0.40 \sim 1.41$ & 0.37 \\
HbsAg & 0.64 & $0.10 \sim 1.55$ & 0.27 \\
AFP, ng/ml & 2.38 & $1.45 \sim 4.20$ & $0.02^{*}$ \\
Cirrhosis & 1.20 & $0.36 \sim 3.94$ & 0.77 \\
Tumor size, cm & 2.21 & $1.14 \sim 4.27$ & $0.02^{*}$ \\
Tumor number & 1.26 & $0.57 \sim 2.79$ & 0.56 \\
AJCC stage & 2.92 & $1.14 \sim 7.50$ & $0.03^{*}$ \\
Metastasis & 1.46 & $0.47 \sim 2.93$ & 0.02 \\
Invasion & 2.67 & $1.35 \sim 3.39$ & $0.01^{*}$ \\
Ki-67 & 2.97 & $1.47 \sim 4.86$ & $0.01^{*}$ \\
$\alpha 1-$ ACT & 1.05 & $1.01 \sim 1.09$ & $0.02^{*}$ \\
\hline
\end{tabular}

flow cytometry results showed that apoptosis was significantly elevated in the cells transfected with pLV- $\alpha 1-A C T-G F P$ (vs. the pLV-GFP groups). Meanwhile, the results showed that the G248-sh1- $\alpha 1$-ACT-GFP- and G248-sh2- $\alpha 1$-ACT-GFP-transfected groups exhibited suppression of cell apoptosis (vs. the G248-GFP groups)(Fig. 4a).To further investigate the mechanisms underlying thea1-ACT-induced apoptosis in the 97 $\mathrm{H}$ and Huh7 cells, we also examined the protein expression of molecules that maybe involved in the apoptotic pathway, such as Bcl2,cleaved PARP, Bax and Bad. As shown in Fig. 4c, the levels of activation of cleaved PARP,Bax,Bad increased, while the level of activation of Bcl2 decreased in the Huh7 cells transfected with pLV- $\alpha 1$-ACT-GFP compared with the cells transfected with pLV-GFP. Meanwhile, the levels of activation of cleaved PARP, Bax and Bad were decreased,but the 
Fig. 3. $\alpha 1$-ACT affected HCC cell proliferation and colony formation in vitro. The Western blot (A) and qRT-PCR (B) confirmed that the lentivirus mediates $\alpha 1$ ACT down-regulation and up-regulation in the $97 \mathrm{H}$ and Huh7 cells, respectively. $* * * \mathrm{p}<0.001$. (C)A CCK8 assay demonstrated that high expression of $\alpha 1$-ACT inhibits HCC cell proliferation and down-regulation of this gene promotes HCC cell proliferation. $* * * \mathrm{p}<0.001$. (D) The dysregulation of $\alpha 1$ ACT affected HCC cell colony formation in vitro. ${ }^{* * *} \mathrm{p}<0.001$.

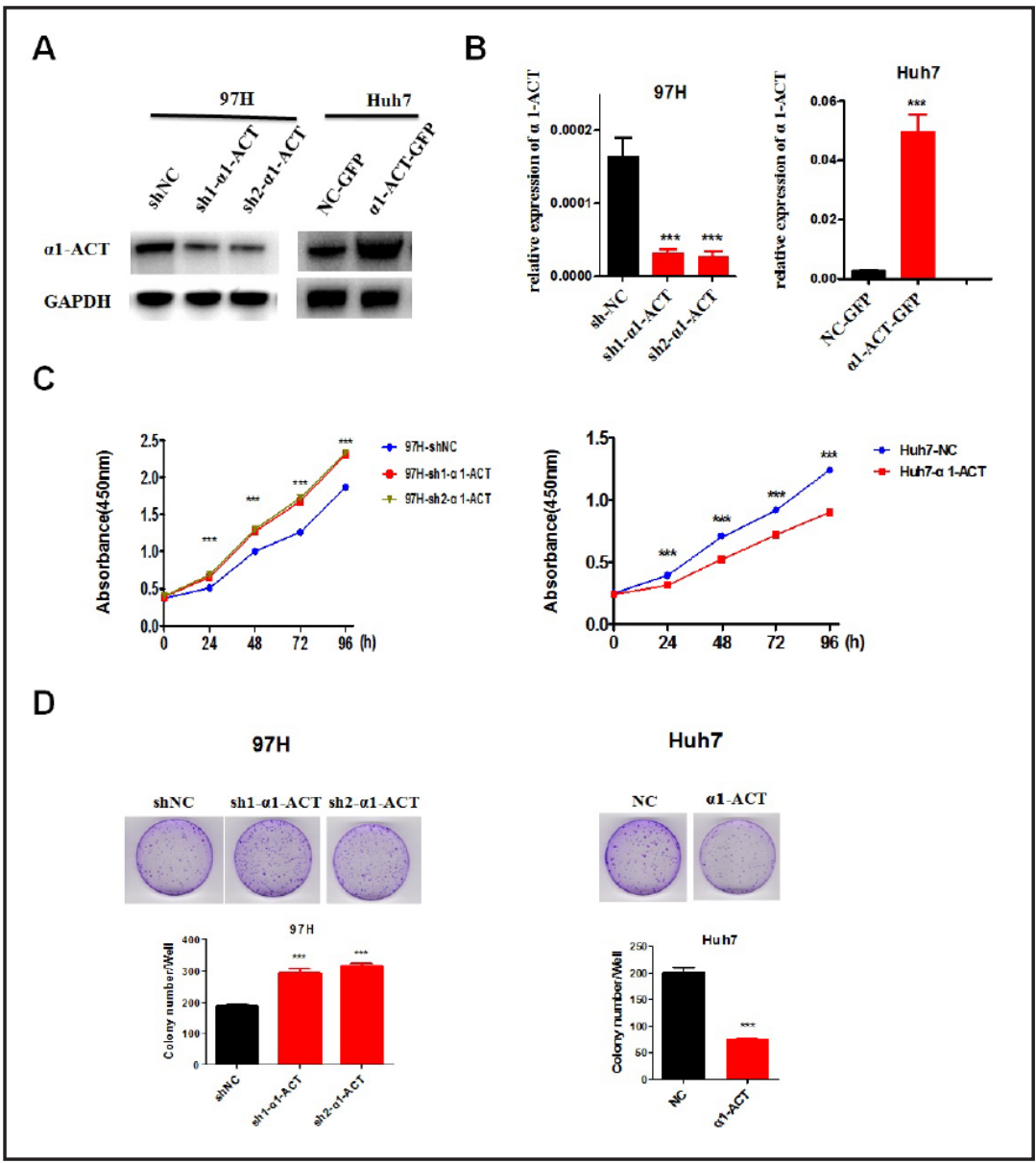

level of activation of Bcl 2 was increased in the $97 \mathrm{H}$ cells transfected with G248-sh1- $\alpha 1$-ACTGFP and G248-sh2- $\alpha 1$-ACT-GFPcompared with the cells transfected with G248-GFP.These results indicated that the overexpression of $\alpha 1$-ACT could promote HCC cell apoptosis by inhibiting the cleaved PARP and Bcl2 apoptotic pathway.

The cell cycle distribution analysis revealed that transfection of the Huh7 cells with pLV- $\alpha 1$-ACT-GFP induced the cell cycle arrestin the G0/G1 phase (vs. pLV-GFP group). A higher proportion of the cells was observed in the G0/G1phases, and a significantly lower proportion of the cells was found in both the S and G2/M phases (Fig.4b). Conversely, the cell cycle distribution analysis in the 97H cells transfected with G248-sh1- $\alpha 1$-ACT-GFP and G248-sh2- $\alpha 1$-ACT-GFP showed an inverse result (vs. the G248-GFP group) (Fig. 4b). Our mechanistic investigations demonstrated that the overexpression of $\alpha 1$-ACT promoted the protein level of p21, which can induce the cell cycle arrest in the G0/G1 phase (Fig. 4d).

a1-ACTcaninhibit the migration and invasion abilities of the HCC cells by regulating MMP2 and MMP9

The wound healing assays revealed decreased motility of the Huh7 cells transfected with pLV- $\alpha 1-A C T-G F P(v s$. the pLV-GFP group), while the 97H cells transfected with G248- sh1$\alpha 1-A C T-G F P$ and G248-sh2- $\alpha 1-A C T-G F P$ exhibited increased motility (vs.G248- GFP group) (Fig. 5a).We next tested the effect of overexpression of $\alpha 1$-ACT on the invasive behaviour of the Huh7 cells and tested the effect of knockdown of 1 1-ACT on the invasive behaviour of the $97 \mathrm{H}$ cells by an in vitro invasion assay. The results revealed decreased invasion of the Huh7 cells transfected with pLV- $\alpha 1$-ACT-GFP(vs. the pLV-GFP groups);on the other hand, the results showed increased invasion of the HCC cells after knockdown of $\alpha 1$-ACT(vs. the G248GFP groups)(Fig. 5b). The mechanistic investigations demonstrated that overexpression 
A

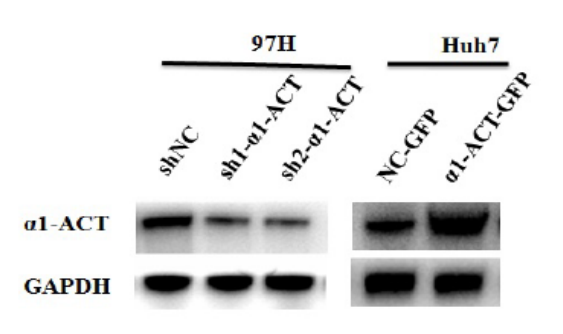

C

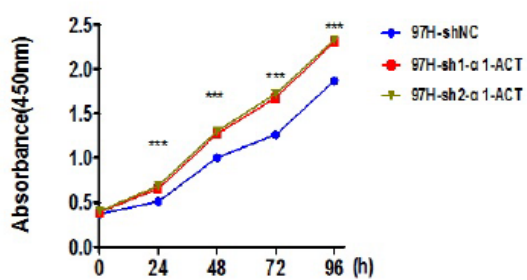

D

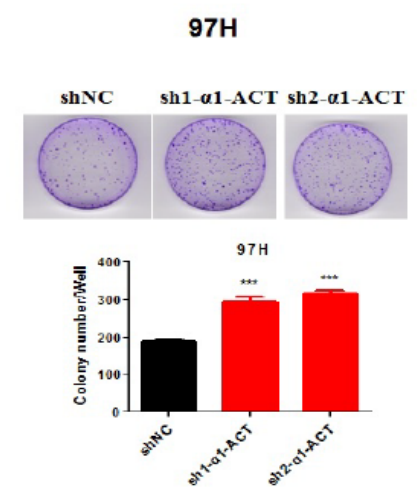

B
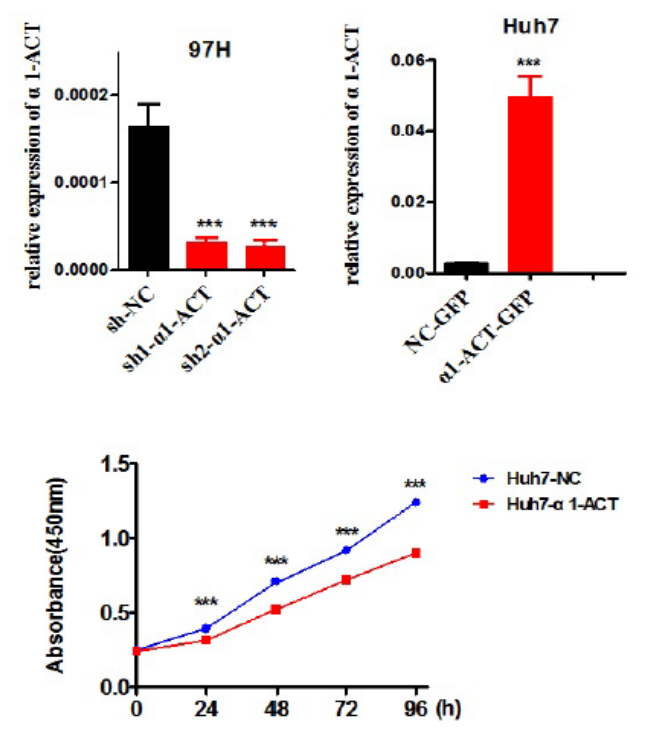

Huh7
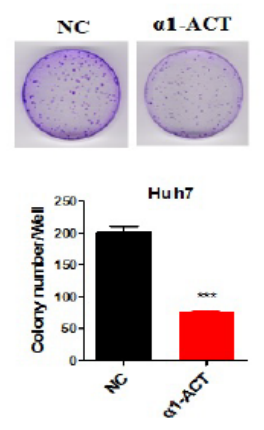

Fig. 4. $\alpha 1$-ACT increases apoptosis in HCC cells and induces cell cycle arrest. (A) Knockdown of $\alpha 1-\mathrm{ACT}$ significantly reduces $97 \mathrm{H}$ cell apoptosis, and overexpression of $\alpha 1$-ACT induces Huh7 cell apoptosis. ${ }^{* * *} \mathrm{p}<0.001$. (B)The FACS analysis revealed $\alpha 1$-ACT overexpression in the $97 \mathrm{H}$ cells and $\alpha 1$-ACT underexpression in the Huh7 cells cycle. ${ }^{* * *} \mathrm{p}<0.001$. The Western blot demonstrates the effect of $\alpha 1$-ACT expression level on apoptosis-related proteins (C: Bcl2, Bax, Bad and cleaved PARP) and the G1 arrest protein, p21 (D).

of $\alpha 1$-ACT limited the MMP2/9 function, which can affect invasion (Fig. 5c). These results indicate that $\alpha 1$-ACT could inhibit HCC cell migration and invasion by regulating the MMP2 and MMP9 proteins.

a1-ACT inhibited the PI3K/AKT/mTOR signalling pathway in the HCC cells

The PI3K/AKT/mTOR pathway plays an important role in tumour growth [23], and the Bcl-2 family proteins function as critical modulators of cell apoptosis [24].We examined the change in the expression levels of molecules in the PI3K/AKT/mTOR pathway and the levels of the Bcl-2 family proteins. As shown in Fig. 6, overexpression of $\alpha 1$-ACT led to decreased phospho-PI3K p85, p-Akt(ser473), and p-mTOR levels in the Huh7 cells. Meanwhile, cleaved PARP and the pro-apoptotic proteins Bax and Bad were increased, while the anti-apoptotic protein Bcl-2 was decreased. After we knocked down $\alpha 1$-ACT, we found over-activation of the PI3K/AKT/mTOR signalling pathway in the 97H cells (Fig. 6). 


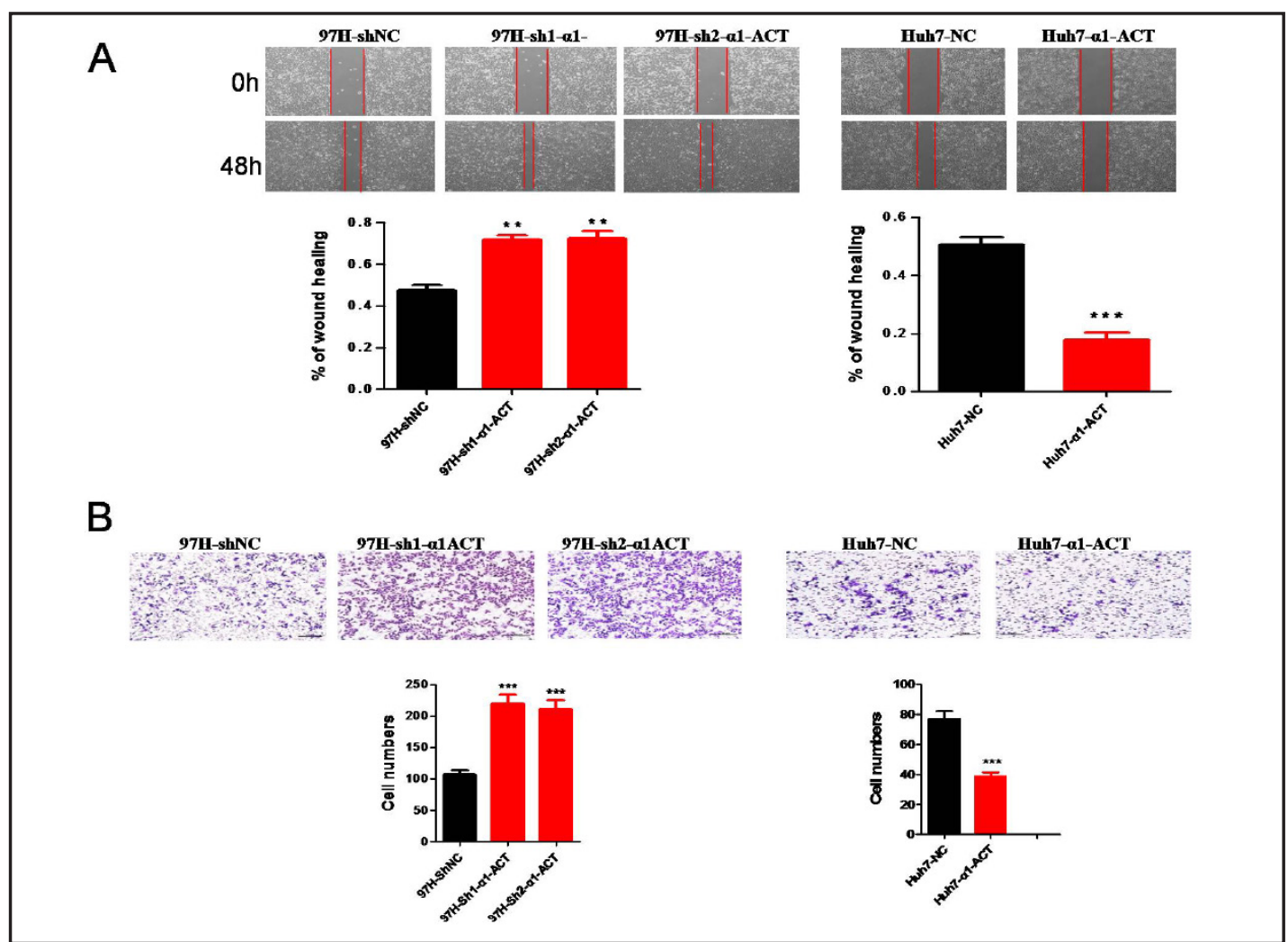

Fig. 5. The migration and invasion abilities of HCC cells were regulated by $\alpha 1$-ACT. The down-regulation of $\alpha 1$-ACT improved the migration (A, left) and invasion (B, left) abilities of the 97H cells, and the up-regulation of $\alpha 1$-ACT abrogates the migration (A, right) and invasion (B, right) abilities of the Huh7 cells. (C) The protein levels of MMP2 and MMP9 are regulated by $\alpha 1$-ACT.

Fig. 6. $\alpha 1-\mathrm{ACT}$ inhibits the PI3K/AKT/ mTOR signalling pathway. Analysis ofthe activity of the PI3K/AKT/mTOR signalling pathway in the $\alpha 1$-ACTdown-regulated $97 \mathrm{H}$ cells (A) and the $\alpha 1$-ACToverexpressed Huh7 cells(B) by Western blot.

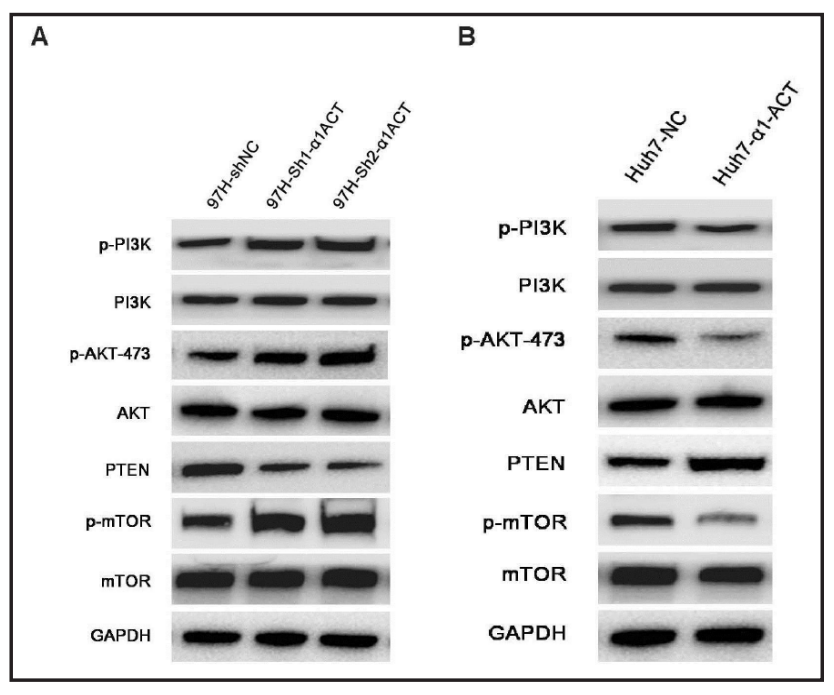

a1-ACT directly bound to PTEN and did not interact with PI3K

To understand the relationship between $\alpha 1$-ACT and PTEN, we determined whether $\alpha 1-A C T$ can bind to PTEN directly.We immunoprecipitated lysates of the pLV- $\alpha 1$ ACT-GFP-transfected Huh7 cells with an anti-PTEN antibody and found that PTEN co-immunoprecipitated with $\alpha 1$-ACT (Fig. 7a). In addition, we also performed another co-immunoprecipitation to determine whether a1-ACT could directly bind to PI3K.

\section{KARGER}


Fig. 7. Lysates of the pLV- $\alpha 1-A C T-G F P-$ transfected Huh7 cells were immunoprecipitated with an anti-PTEN antibody, and PTEN was co-immunoprecipitated with $\alpha 1$-ACT (Fig. 7a). Immunoblotting of the anti-PI3K immunoprecipitates from the pLV- $\alpha 1$ - ACT- GFP-transfected Huh7 cells showed that PI3K could not co-immunoprecipitate with $\alpha 1$-ACT. (Fig. 7b).

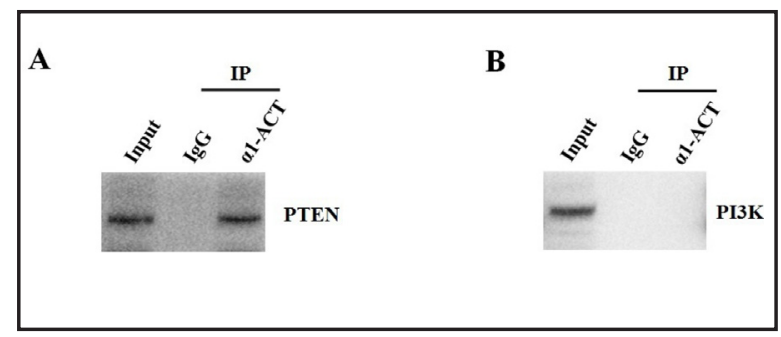

Fig. 8. $\alpha 1$-ACT blocked HCC tumourigenesis and the PI3K/ AKT/mTOR signal pathway in vivo. (A) The photograph and average tumour weight of the control and $\alpha 1$-ACT-knockdown/ overexpressed xenografts at the end point. (B) The In vivo tumour growth curve of the $\alpha 1$-ACT knockdown and overexpressed xenografts over 30 days. (C)The IHC staining shows Ki-67, p21, cleaved PARP, Bcl2,Bad and Bax in each tumour group. (D)The IHC stainingof the molecules in the PI3K/AKT/mTOR signalling pathway in xenograft tumours is shown.

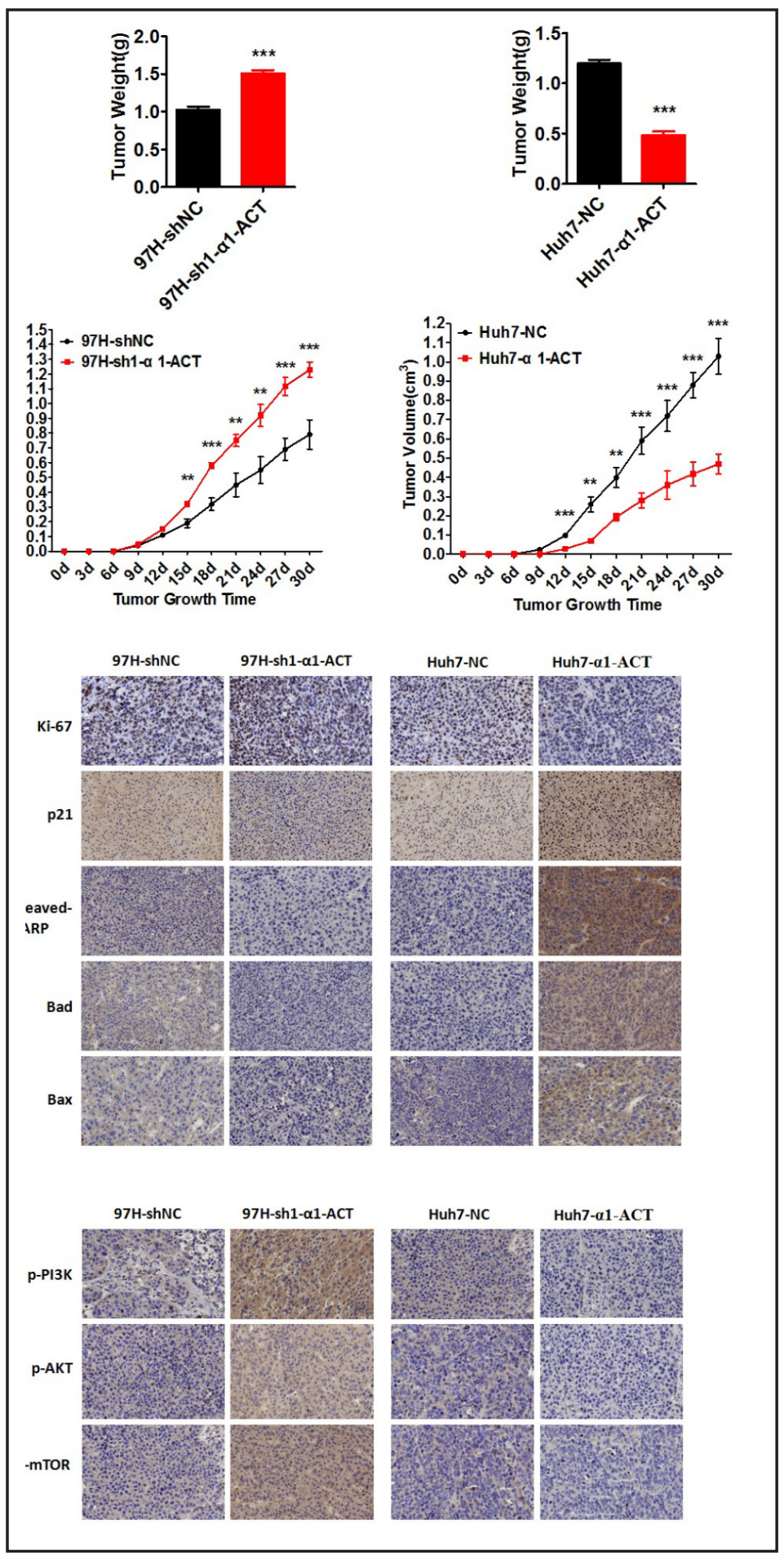




\section{Cellular Physiology Cell Physiol Biochem 2017;41:2289-2306 \\ and Biochemistry Published online: April 26, $2017 \quad \begin{aligned} & \text { DOI: 10.1159/000475648 } 2017 \text { The Author(s). Published by S. Karger AG, Basel } \\ & \text { www.karger.com/cpb }\end{aligned}$ \\ Zhu et al.: $\alpha 1-$ ACT Inhibits Hepatocellular Carcinoma}

Immunoblotting of the anti-PI3K immunoprecipitates from the pLV- $\alpha 1$-ACT- GFP- transfected Huh7 cells revealed that PI3K did not co-immunoprecipitate with $\alpha 1$-ACT. (Fig. 7b).

11-ACT inhibited HCC tumourigenesis

To explore whether $\alpha 1$-ACT affected tumourigenesis in vivo,the pLV- $\alpha 1-A C T-G F P-a n d$ pLV-GFP-transfected Huh7 cells and the G248-sh1- $\alpha 1$-ACT-GFP- and G248-GFP- transfected $97 \mathrm{H}$ cells were injected into male BALB/c nude mice. We found that the tumour xenograft volume in the pLV- $\alpha 1-A C T-G F P$ group was smaller than that in the pLV-GFP group (Fig. $8 \mathrm{a}, \mathrm{P}<0.01$ ), and the tumour weight was also lighter in the pLV- $\alpha 1$ - ACT-GFP group(Fig. 8a, $\mathrm{P}<0.01$ ). The tumour xenograft growth in the $\mathrm{pLV- \alpha 1-ACT-GFP} \mathrm{group} \mathrm{was} \mathrm{slower} \mathrm{than} \mathrm{that} \mathrm{in}$ the pLV-GFP group on the $12^{\text {th }}$ day(Fig. $8 \mathrm{~b}$ ).Meanwhile, the tumour volume and weight were greater in the tumour xenograft of the G248-sh1- $\alpha 1$ - ACT-GFP group than in the G248-GFP group(Fig. $8 \mathrm{a}, \mathrm{P}<0.05)$. The tumour xenograft growth in the pLV-sh1- $\alpha 1-\mathrm{ACT}$-GFP group was faster than that in the G248-GFP group on the $15^{\text {th }}$ day (Fig. 8b).All these results suggested that overexpression of $\alpha 1$-ACT may suppress tumour growth in vivo.

We performed an immunohistochemistry assay to determine the expression of the cell proliferation, cell cycle and cell apoptosis marker proteins (Ki-67, p21, cleaved PARP, Bcl2, Bad and Bax) in the xenograft tumour tissues. As shown in Fig. 8c, $\alpha 1$-ACT inhibited HCC cell proliferation and induced cell apoptosis and cell cycle arrest. The activation of the PI3K/ AKT/mTOR signalling pathway was also abrogated by $\alpha 1-\mathrm{ACT}$ in vivo (Fig. 8d). These data also support the notion that $\alpha 1$-ACT inhibited the PI3K/AKT/mTOR signalling pathway and HCC tumourigenesis in vivo.

\section{Discussion}

Despite the improvements in surveillance and clinical treatment strategies for HCC, the prognosis of HCC remains poor because of the high rates of recurrence and metastasis [25, 26]. Finding novel molecular targets relevant to the prognosis and development of HCC for clinical practitioner and basic scientists is a substantial challenge. Previously, Santamaria et al. found that $\alpha 1$-ACT localizes tothe nuclei of hepatic cells and inhibits proliferation through promotion of chromatin condensation. Overexpression of $\alpha 1$-ACT slows the growth of HCC xenograft tumours in nude mice [11]. In this study, we found that the majority of Chinese clinical HCC samples have low $\alpha 1$-ACT expression compared with the adjacent non-cancerous tissues. In addition, we found that the expression of $\alpha 1$-ACT was significantly correlated with the AJCC stage, serum level of AFP, the expression of Ki67, and prognosis. There was a remarkable positive correlation between the expression levels of $\alpha 1-\mathrm{ACT}$ and cleaved PARP in the 96 pairs of HCC tissues, which was determined using Spearman's correlation coefficient. Univariate and multivariate analyses also indicated that $\alpha 1$-ACT could be an independent prognostic indicator of patient survival.

Moreover, we found that interference with $\alpha 1-\mathrm{ACT}$ in the $97 \mathrm{H}$ cells led to accelerated cell growth, increased cell migration, enhanced cell invasion, decreased G0/G1 phase in the cell cycle and suppressed apoptosis, whereas overexpression of $\alpha 1$-ACT in the Huh7 cells induced the opposite effects. Further investigation indicated that $\alpha 1$-ACT induces cell cycle arrest in the G0/G1 phase by upregulating the expression of p21 and inhibiting the invasion of HCC cells by suppressing MMP2 and MMP9. These results were consistent with previous studies; p21, which belongs to the Cip/Kip family, negatively regulates the cell cycle progression through the inhibition of the CDK-cyclin complexes [27-30]. MMP2 and MMP9 are important for degrading basement membrane components and have been demonstrated to facilitate tumour invasion and metastasis in many types of cancer cells [31-33]. Several recent studies have shown that the activation of the PI3K/AKT signalling pathway correlates with increased expression of MMP-2 and MMP-9 at protein level and promotes cancer cell invasion [34-39]. Among these studies, some authors have noted that PTEN suppresses the PI3K/Akt pathway to inhibit the expression levels of the MMP2 and MMP9 proteins [35, 39]. In addition, Jiang 
et al. reported that CYP3A5 overexpression limited MMP2/9 function and suppressed HCC migration and invasion both in vitro and in vivo by inhibiting mTORC2/AKT signalling [38]. In all of the above mentioned studies, activation of the PI3K/AKT signalling pathway results in the elevation of MMP2/MMP9 via a currently unknown mechanism. We speculate that $\alpha 1$-ACT regulates the expression levels of MMP2 and MMP9 by activating intracellular PI3KAKT-mTOR-dependentproteolytic enzyme signalling, and a more in-depth analysis of this mechanism will be addressed in a future study. In contrast with our study, Santamaria et al. have found that $\alpha 1$-ACT inhibits cell cycle progression and anchorage-independent proliferation of HCC cells by tightly binding to the chromatin to promote a condensed state [11]. In endometrial cancer, Yang et al. demonstrated that $\alpha 1$-ACT promoted endometrial cancer cell proliferation by regulating the G2/M checkpoint in the cell cycle and inhibited cell apoptosis. The authors further discovered that the pro-proliferative effect of $\alpha 1$-ACT on endometrial cancer was likely due to the activation of MAPK/ERK1/2 and PI3K/AKT/mTOR signalling [40]. In our study, we found that $\alpha 1$-ACT inhibited hepatocellular carcinoma cells by suppressing the PI3K/AKT/mTOR axis to regulate the apoptosis-related proteins. The $\mathrm{PI} 3 \mathrm{~K} / \mathrm{AKT} / \mathrm{mTOR}$ pathway serves as a proto-oncogenic pathway, which is critical for cancer progression, including cellular proliferation, growth, survival, and drug resistance [41]. Overactivation of the signalling pathway has been observed in a variety of tumours,including hepatocellular carcinoma, ovarian cancer, multiple myeloma, breast cancer, prostate cancer, and others [42-45].Our results demonstrated that $\alpha 1$-ACT may modulate HCC cell viability by inducing cell cycle arrest and promoting cell apoptosis through inhibiting the PI3K/AKT/ mTOR signalling pathway.

A previous study showed that suppression of the PI3K/AKT/mTOR pathway can induce cell apoptosis and mitochondrial damage by the Bcl2 pathway [46]. On the other hand, suppression of the PI3K/AKT/mTOR pathway can induce transcriptional activity of FOXO3a to down-regulate MnSOD, which leads to increased levels of ROS that induce activation of the p53/p21 pathway [47].Meanwhile, activation of AKT can suppress the apoptosis-associated protein Bad to inhibit apoptosis and counteract the function of p21 to reduce the G0/G1 phase of the cell cycle and accelerate cycle progression $[48,49]$. We investigated whether the cell cycle and apoptosis-associated proteins that are downstream of the PI3K/AKT/ mTOR pathway were regulated by $\alpha 1-A C T$. We found that the pro-apoptotic proteins, such as cleaved PARP, Bad and Bax and the cell cycle-associated protein p21, were increased, while the anti-apoptotic protein Bcl-2 decreased in the presence of $\alpha 1$-ACT.

PTEN acts as an inhibitor of the PI3K/Akt pathway and can inhibit tumour cell growth and invasion by directly suppressing the PI3k/AKT pathway [21]. On the other hand, there was a negative feedback relationship between p-PI3K and PTEN, which indicates that a decrease in p-PI3K can also cause an increase in PTEN [22].In our study, we found that the increase in PTEN was accompanied by the overexpression of $\alpha 1$-ACT; therefore, we next conducted a more in-depth study to elucidate the mechanism underlying the regulation of PTEN expression by 1 1-ACT. We performed a co-immunoprecipitation experiment to determine whether the $\alpha 1$-ACT protein extracted from the Huh7 cells transfected with an $\alpha 1$ ACT expression vector could bind to the PTEN protein in the HCC cells. We also performed another co-immunoprecipitation experiment and found that there is no binding between the $\alpha 1$-ACT protein and the PI3K protein.

To date, no report has demonstrated that significant up-regulation of $\alpha 1$-ACT expression levels in the liver during the acute-phase response can lead to hepatocellular apoptosis. However, in our study, we found that overexpression of $\alpha 1$-ACT in the HCC cells can induce apoptosis. This differential response may be due to the differential proliferative status of the hepatocytes in the liver (quiescence), and $\alpha 1$-ACT may have stronger apoptotic effects on the HCC cells (active proliferation). In addition, many cytokines similar to interleukin1(IL-1) and interleukin-6(IL-6)that are involved in the acute-phase response (APR)are intimately involved in hepatic regulation of the APR [50]. STAT3, which activates many types of cytokine-driven inflammatory genes, is significantly up-regulated as a transcription factor that interacts with the APR elements when IL-6 induces the acute-phase response in the 


\section{Cellular Physiology Cell Physiol Biochem 2017;41:2289-2306

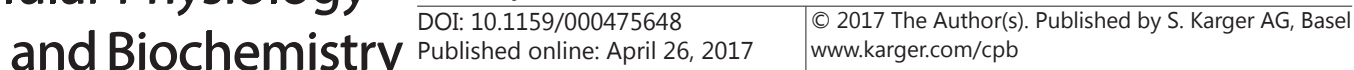 \\ Published online: April 26, 2017,}

liver during inflammation [51].The transcription factor STAT-3 becomes activated via Janus kinases (JAKs), which results in the induction of STAT-3-related genes, such as c-myc, that promote cell proliferation [52]. This effect may counteract the apoptosis induced by the overexpression of $\alpha 1$-ACT in the liver during the acute-phase response.IL- 6 binds to the IL- 6 receptor (IL-6R) and leads to the activation of the tyrosine kinase JAK1, which induces the activation of several intracellular signalling pathways,including the MAPK and PI3K pathway. This may offset the inhibitory effect of $\alpha 1-A C T$ on the PI3K/AKT/mTOR signalling pathway [53].

Our mouse xenograft models confirmed that $\alpha 1$-ACT inhibited the growth of the subcutaneously implanted tumours and promoted cell apoptosis by inhibiting the PI3K/ AKT/mTOR signalling pathway. These results were consistent with the results of vitro experiments.

For the first time, this study showed the decreased expression levels of $\alpha 1$-ACT in HCC tissues,which were correlated with the plasma levels of AFP, the AJCC stage, cleaved PARP and poor prognosis. In addition, the COX regression analysis demonstrated that 1 1-ACT could be an independent prognostic factor for the survival of HCC patients. We also found that $\alpha 1-\mathrm{ACT}$ induces cellular apoptosis and cell cycle arrest. Finally, we demonstrated that overexpression of $\alpha 1$-ACT promoted cell apoptosis in the HCC cells via inhibiting the PI3K/ AKT/mTOR signalling pathway both in vitro and in vivo. Our findings indicated that $\alpha 1$-ACT may be a novel potential target for the development of diagnostic and therapeutic strategies for HCC. On the other hand, $\alpha 1$-ACT could also serve as a prognostic marker for HCC.

\section{Acknowledgements}

This work was supported by grants from the National Natural Science Foundation for Distinguished Young Scholars (Grant Number: 81225017 to B.S.), the National Key Research and Development Programme of China (Grant Number: 2016YFC0905900 to B.S.) and the State Key Programme of National Natural Science of China (Grant Number: 81430062 to B.S.) and the National Natural Science Foundation of China (Grant Number: 81521004 to B.S.). This work was also supported in part by the Programme for the Development of Innovative Research Teams in the First Affiliated Hospital of Nanjing Medical University, and the Priority Academic Programme of Jiangsu Higher Education Institutions. B.S. is a Yangtze River Scholar Distinguished professor.

\section{Disclosure Statement}

There are no potential conflicts of interest.

\section{References}

$\checkmark$ Colombo N, Preti E, Landoni F, Carinelli S, Colombo A, Marini C, Sessa C, Group EGW: Endometrial cancer: ESMO Clinical Practice Guidelines for diagnosis, treatment and follow-up. Ann Oncol 2013;24 Suppl 6:vi3338.

2 Bruix J, Gores GJ, Mazzaferro V: Hepatocellular carcinoma: clinical frontiers and perspectives. Gut 2014;63:844-855.

-3 Zhang L, Jia G, Shi B, Ge G, Duan H, Yang Y: PRSS8 is Downregulated and Suppresses Tumour Growth and Metastases in Hepatocellular Carcinoma. Cell Physiol Biochem 2016;40:757-769.

4 Moudgil V, Redhu D, Dhanda S, Singh J: A review of molecular mechanisms in the development of hepatocellular carcinoma by aflatoxin and hepatitis B and C viruses. J Environ Pathol Toxicol Oncol 2013;32:165-175.

5 Finn RS: Development of molecularly targeted therapies in hepatocellular carcinoma: where do we go now? Clin Cancer Res 2010;16:390-397. 


\section{Cellular Physiology Cell Physiol Biochem 2017;41:2289-2306 \begin{tabular}{l|l} 
and Biochemistry Published online: April 26, 2017 & $\begin{array}{l}\text { C } 2017 \text { The Author(s). Published by S. Karger AG, Basel } \\
\text { www.karger.com/cpb }\end{array}$ \\
\hline
\end{tabular}

6 Hang X, Zhu S, Di H, Wu Z, Chu K, Wang J, Xin H, Yu G, Peng H, Miao X, Xu W: NEDD4 Depletion Inhibits Hepatocellular Carcinoma Growth via Targeting PTEN. Cell Physiol Biochem 2016;39:768-779.

7 Tang W, Feng X, Zhang S, Ren Z, Liu Y, Yang B, lv B, Cai Y, Xia J, Ge N: Caveolin-1 Confers Resistance of Hepatoma Cells to Anoikis by Activating IGF-1 Pathway. Cell Physiol Biochem 2015;36:1223-1236.

8 Baker C, Belbin 0, Kalsheker N, Morgan K: SERPINA3 (aka alpha-1-antichymotrypsin). Front Biosci 2007;12:2821-2835.

-9 Slowik A, Borratynska A, Turaj W, Pera J, Dziedzic T, Figlewicz DA, Betlej M, Krzyszkowski T, Czepko R, Szczudlik A: Alpha1-antichymotrypsin gene (SERPINA3) A/T polymorphism as a risk factor for aneurysmal subarachnoid hemorrhage. Stroke 2005;36:737-740.

10 Licastro F, Chiappelli M, Caldarera CM, Porcellini E, Carbone I, Caruso C, Lio D, Corder EH: Sharing pathogenetic mechanisms between acute myocardial infarction and Alzheimer's disease as shown by partially overlapping of gene variant profiles. J Alzheimers Dis 2011;23:421-431.

-11 Santamaria M, Pardo-Saganta A, Alvarez-Asiain L, Di Scala M, Qian C, Prieto J, Avila MA: Nuclear alpha1antichymotrypsin promotes chromatin condensation and inhibits proliferation of human hepatocellular carcinoma cells. Gastroenterology 2013;144:818-828.e814.

-12 Matter MS, Decaens T, Andersen JB, Thorgeirsson SS: Targeting the mTOR pathway in hepatocellular carcinoma: current state and future trends. J Hepatol 2014;60:855-865.

13 Fornaro L, Vivaldi C, Caparello C, Sacco R, Rotella V, Musettini G, Luchi S, Baldini EE, Falcone A, Masi G: Dissecting signaling pathways in hepatocellular carcinoma: new perspectives in medical therapy. Future Oncol 2014;10:285-304.

-14 Papadimitrakopoulou V: Development of PI3K/AKT/mTOR pathway inhibitors and their application in personalized therapy for non-small-cell lung cancer. J Thorac Oncol 2012;7:1315-1326.

-15 Wolin EM: PI3K/Akt/mTOR pathway inhibitors in the therapy of pancreatic neuroendocrine tumors. Cancer Lett 2013;335:1-8.

16 Mazzoletti M, Broggini M: PI3K/AKT/mTOR inhibitors in ovarian cancer. Curr Med Chem 2010;17:44334447.

17 Porta C, Paglino C, Mosca A: Targeting PI3K/Akt/mTOR Signaling in Cancer. Front Oncol 2014;4:64.

18 Fulda S: Modulation of mitochondrial apoptosis by PI3K inhibitors. Mitochondrion 2013;13:195-198.

19 Fulda S: Synthetic lethality by co-targeting mitochondrial apoptosis and PI3K/Akt/mTOR signaling. Mitochondrion 2014;19 Pt A:85-87.

20 Yao Y, Dou C, Lu Z, Zheng X, Liu Q: MACC1 suppresses cell apoptosis in hepatocellular carcinoma by targeting the HGF/c-MET/AKT pathway. Cell Physiol Biochem 2015;35:983-996.

21 Tamura M, Gu J, Tran H, Yamada KM: PTEN gene and integrin signaling in cancer. J Natl Cancer Inst 1999;91:1820-1828.

22 Carracedo A, Pandolfi PP: The PTEN-PI3K pathway: of feedbacks and cross-talks. Oncogene 2008;27:55275541.

23 Dent P: Crosstalk between ERK, AKT, and cell survival. Cancer Biol Ther 2014;15:245-246.

24 Adams JM, Cory S: The Bcl-2 protein family: arbiters of cell survival. Science 1998;281:1322-1326.

25 Colombo M, Sangiovanni A: Treatment of hepatocellular carcinoma: beyond international guidelines. Liver Int 2015;35:129-138.

26 Bruix J, Reig M, Sherman M: Evidence-Based Diagnosis, Staging, and Treatment of Patients With Hepatocellular Carcinoma. Gastroenterology 2016;150:835-853.

-27 Schwartz GK: CDK inhibitors: cell cycle arrest versus apoptosis. Cell Cycle 2002;1:122-123.

28 Chang KL, Kung ML, Chow NH, Su SJ: Genistein arrests hepatoma cells at G2/M phase: involvement of ATM activation and upregulation of p21waf1/cip1 and Wee1. Biochem Pharmacol 2004;67:717-726.

-29 Evdokiou A, Raggatt LJ, Atkins GJ, Findlay DM: Calcitonin receptor-mediated growth suppression of HEK293 cells is accompanied by induction of p21WAF1/CIP1 and G2/M arrest. Mol Endocrinol 1999;13:17381750.

30 Choi YH, Zhang L, Lee WH, Park KY: Genistein-induced G2/M arrest is associated with the inhibition of cyclin B1 and the induction of p21 in human breast carcinoma cells. Int J Oncol 1998;13:391-396.

-31 Egeblad M, Werb Z: New functions for the matrix metalloproteinases in cancer progression. Nat Rev Cancer 2002;2:161-174.

-32 Coussens LM, Fingleton B, Matrisian LM: Matrix metalloproteinase inhibitors and cancer: trials and tribulations. Science 2002;295:2387-2392. 


\section{Cellular Physiology Cell Physiol Biochem 2017;41:2289-2306 \begin{tabular}{ll|l} 
and Biochemistry Published online: April 26, 2017 & $\begin{array}{l}\text { (c) } 2017 \text { The Author(s). Published by S. Karger AG, Basel } \\
\text { www.karger.com/cpb }\end{array}$
\end{tabular}

33 Gao J, Ding F, Liu Q Yao Y: Knockdown of MACC1 expression suppressed hepatocellular carcinoma cell migration and invasion and inhibited expression of MMP2 and MMP9. Mol Cell Biochem 2013;376:21-32.

34 Tang Y, Lv P, Sun Z, Han L, Zhou W: 14-3-3beta Promotes Migration and Invasion of Human Hepatocellular Carcinoma Cells by Modulating Expression of MMP2 and MMP9 through PI3K/Akt/NF-kappaB Pathway. PLoS One 2016;11:e0146070.

-35 Tian T, Nan KJ, Guo H, Wang WJ, Ruan ZP, Wang SH, Liang X, Lu CX: PTEN inhibits the migration and invasion of HepG2 cells by coordinately decreasing MMP expression via the PI3K/Akt pathway. Oncol Rep 2010;23:1593-1600.

-36 Gao Y, Guan Z, Chen J, Xie H, Yang Z, Fan J, Wang X, Li L: CXCL5/CXCR2 axis promotes bladder cancer cell migration and invasion by activating PI3K/AKT-induced upregulation of MMP2/MMP9. Int J Oncol 2015;47:690-700.

37 Liu T, Zhou W, Cai B, Chu J, Shi G, Teng H, Xu J, Xiao J, Wang Y: IRX2-mediated upregulation of MMP-9 and VEGF in a PI3K/AKT-dependent manner. Mol Med Rep 2015;12:4346-4351.

- 38 Jiang F, Chen L, Yang YC, Wang XM, Wang RY, Li L, Wen W, Chang YX, Chen CY, Tang J, Liu GM, Huang WT, Xu L, Wang HY: CYP3A5 Functions as a Tumor Suppressor in Hepatocellular Carcinoma by Regulating mTORC2/Akt Signaling. Cancer Res 2015;75:1470-1481.

-39 Shukla S, Maclennan GT, Hartman DJ, Fu P, Resnick MI, Gupta S: Activation of PI3K-Akt signaling pathway promotes prostate cancer cell invasion. Int J Cancer 2007;121:1424-1432.

-40 Yang GD, Yang XM, Lu H, Ren Y, Ma MZ, Zhu LY, Wang JH, Song WW, Zhang WM, Zhang R, Zhang ZG: SERPINA3 promotes endometrial cancer cells growth by regulating G2/M cell cycle checkpoint and apoptosis. Int J Clin Exp Pathol 2014;7:1348-1358.

41 Morgensztern D, McLeod HL: PI3K/Akt/mTOR pathway as a target for cancer therapy. Anticancer Drugs 2005;16:797-803.

42 Panasyuk G, Patitucci C, Espeillac C, Pende M: The role of the mTOR pathway during liver regeneration and tumorigenesis. Ann Endocrinol (Paris) 2013;74:121-122.

43 Zhou L, Huang Y, Li J, Wang Z: The mTOR pathway is associated with the poor prognosis of human hepatocellular carcinoma. Med Oncol 2010;27:255-261.

-44 Polivka J, Jr., Janku F: Molecular targets for cancer therapy in the PI3K/AKT/mTOR pathway. Pharmacol Ther 2014;142:164-175.

45 Morgan TM, Koreckij TD, Corey E: Targeted therapy for advanced prostate cancer: inhibition of the PI3K/ Akt/mTOR pathway. Curr Cancer Drug Targets 2009;9:237-249.

-46 Estan MC, Calvino E, de Blas E, Boyano-Adanez Mdel C, Mena ML, Gomez-Gomez M, Rial E, Aller P: 2-DeoxyD-glucose cooperates with arsenic trioxide to induce apoptosis in leukemia cells: involvement of IGF-1Rregulated Akt/mTOR, MEK/ERK and LKB-1/AMPK signaling pathways. Biochem Pharmacol 2012;84:16041616.

47 Xu Y, Li N, Xiang R, Sun P: Emerging roles of the p38 MAPK and PI3K/AKT/mTOR pathways in oncogeneinduced senescence. Trends Biochem Sci 2014;39:268-276.

48 Liang J, Slingerland JM: Multiple roles of the PI3K/PKB (Akt) pathway in cell cycle progression. Cell Cycle 2003;2:339-345.

49 Cappellini A, Tabellini G, Zweyer M, Bortul R, Tazzari PL, Billi AM, Fala F, Cocco L, Martelli AM: The phosphoinositide 3-kinase/Akt pathway regulates cell cycle progression of HL60 human leukemia cells through cytoplasmic relocalization of the cyclin-dependent kinase inhibitor p27(Kip1) and control of cyclin D1 expression. Leukemia 2003;17:2157-2167.

50 Mortensen RF: C-reactive protein, inflammation, and innate immunity. Immunol Res 2001;24:163-176.

-51 Akira S, Nishio Y, Inoue M, Wang XJ, Wei S, Matsusaka T, Yoshida K, Sudo T, Naruto M, Kishimoto T: Molecular cloning of APRF, a novel IFN-stimulated gene factor 3 p91-related transcription factor involved in the gp130-mediated signaling pathway. Cell 1994;77:63-71.

52 Neurath MF, Finotto S: IL-6 signaling in autoimmunity, chronic inflammation and inflammation-associated cancer. Cytokine Growth Factor Rev 2011;22:83-89.

53 Schmidt-Arras D, Rose-John S: IL-6 pathway in the liver: From physiopathology to therapy. J Hepatol 2016;64:1403-1415. 